DOI: 10.20472/IAC.2019.047.027

YUKI TAKEYAMA

Graduate School of Business Administration and Computer Science, Japan

KATSUNORI FUJII

Graduate School of Business Administration and Computer Science, Japan

TOSHIRO SAKAI

Chube University, Japan

NOZOMI TANAKA

Tokaigakuen University, Japan

YUKI KANI

Graduate School of Business Administration and Computer Science, Aichi Institute of Technology, Japan

YUSAKU OGURA

Graduate School of Business Administration and Computer Science, Aichi Institute of Technology, Japan

\title{
SEARCH FOR OBESITY CUTOFF VALUE BASED ON HEALTH INFORMATION: ANALYSIS FROM BMI FLUCTUATION
}

\begin{abstract}
:
Obesity refers to a state in which excessive fat is accumulated in the body. According to the World Health Organization (WHO), people with a body mass index (BMI) of $\geq 25$ are taken to be obese. This is the standard indicating increased risk of diseases such as myocardial infarction and stroke attributable to obesity. That is, it is considered to be an indicator below which risk is inhibited and people can live in health. However, the critical point for risk affecting health is not clear. If the risks associated with health information could be analyzed by degree of obesity, it may be possible to identify a cut-off value for obesity. In this study we assessed the level of health risk based on BMI fluctuations, calculated the mean health information values for each unit of BMI from 14 to 34, and analyzed fluctuations in each health information item based on BMI fluctuation. The results showed that the risk from blood pressure and maximum oxygen uptake increased together with fluctuations in BMI. With this it is thought that a new cutoff point for obesity risk can be established.
\end{abstract}

\section{Keywords:}

Obesity, Health Information, BMI Fluctuation, Cutoff Value

JEL Classification: 100, I10, I12 